\title{
De Tecún Umán a la Nueva América. Martí y la cultura maya de Guatemala
}

From Tecún Umán to the new América. Martí and the mayar culture of Guatemala.

\section{De Tecún Umán a nova America.}

\section{Martí e a cultura maya da Guatemala}

Pedro Pablo Rodríguez

Historiador

Centro de Estudios Martianos Cuba

Recibido: 4/8/2018

Aceptado: 10/11/2018

DOI: http://doi.org/10.15359/tdna.35-65.2

\section{Resumen}

José Martí (1853-1895), el apóstol de la independencia cubana, fue un admirador de la cultura maya, forjada a través del conocimiento de las evidencias arqueológicas, estudios históricos y antropológicos de su época, como mediante su contacto con personas y comunidades mayas durante su estancia en Guatemala entre 1877 y 1878. Tal conocimiento impulsó su criterio de que esa cultura originaria de nuestra América, al igual que las de otros pueblos prehispánicos, era imprescindible para forjar naciones alejadas de todos los rezagos coloniales.

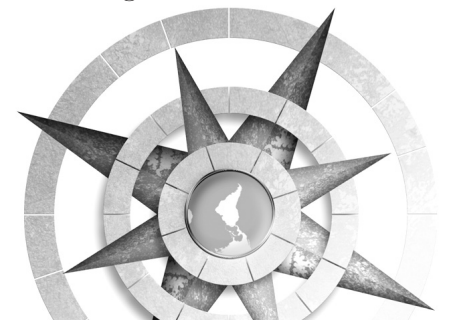

Keywords: José Martí, Maya culture, Guatemala, civilization and barbarism, Latin America.
Palabras clave: José Martí, cultura maya, Guatemala, civilización y barbarie, América Latina

\section{Abstract}

José Martí (1853-1895), the Apostle of Cuban independence, was an admirer the Mayan culture. This admiration was forged through knowledge of archaeological evidence, the historical and anthropological studies from his time, and by his personal contacts with Maya peoples and communities during his residence in Guatemala in 1877 and 1878. That knowledge drove his of view that the culture of Nuestra América [Our America], like that of other pre-Hispanic peoples, was essential to forge nations far removed from all colonial backwardness. 


\section{Resumo}

José Martí (1853-1895), Apostolo da independência cubana, foi admirador da cultura Maya. Esta admiração foi forjada pelo conhecimento das evidências arqueológicas, dos estudos históricos e antropológicos de seu tempo e por seus contatos pessoais com os povos e comunidades Mayas durante sua residência na Guatemala em 1877 e 1878. Esse conhecimento o motivou-le a pensar que a cultura de Nuestra América [Nossa América], como a de outros povos pré-hispânicos, era essencial para forjar nações distantes de qualquer atraso colonial.

Palavras chave: José Martí, cultura Maia, Guatemala, civilização e barbárie, Latino-América

Las primeras referencias explícitas a la cultura maya las encontramos en la obra de José Martí, justamente durante su viaje hacia Guatemala y, sobre todo su estancia en ese país entre 1877 y 1878.

Es altamente probable, sin embargo, que desde fecha muy anterior el cubano haya tenido noticias de ella, desde su adolescencia en Cuba, tanto por las lecturas en la biblioteca particular, como por las conversaciones con el guatemalteco Bernardo Valdés-Domínguez, el padre de sus compañeros de colegio y grandes amigos de siempre Eusebio y Fermín Valdés-Domínguez. A la información libresca pudo haberse sumado la presencia de los numerosos mayas enviados en condiciones de esclavitud a Cuba, durante la guerra de castas en Yucatán, tema abordado en la prensa y en los círculos intelectuales y políticos insulares. Como tampoco es descartable que durante su residencia en la Ciudad de México entre 1875 y 1877, Martí haya alcanzado algún grado de conocimiento acerca de los mayas.

Tales noticias y conocimientos previos, más los descubrimientos arqueológicos por aquella época de varias ciudades antiguas de los mayas en Yucatán, sin duda fueron los impulsores de su insólito recorrido para entonces hacia Guatemala, bordeando aquella península para emprender luego camino hacia la capital desde el puerto de Livingston a través de la Sierra de las Minas.

El contacto directo con los mayas se había iniciado semanas antes, pues Martí había llegado el 28 de febrero de 1877 a Progreso procedente de La Habana, y en carta a su amigo Manuel Mercado, en la Ciudad de México, le comunicó que marcharía a Mérida: "de aquí 5 días volveré a embarcarme para Isla de Mujeres" (Martí, Tomo 5, p. 29). En esta ciudad se reunió con miembros de la colonia cubana allí asentada, particularmente con Rodolfo Menéndez de la

1 José Martí. Obras completas, Edición Crítica. La Habana, Centro de Estudios Martianos, 2009, tomo 5, p. 29. En lo adelante se cita OCEC, el primer número corresponde al tomo y los siguientes a las páginas. 
Peña, muy al tanto de las investigaciones en los sitios de los antiguos mayas. Se estima como probable que visitara las ruinas de Uxmal y de Chichén Itzá, y que fue en aquella ciudad donde vio la escultura llamada Chacmool, de la cual hizo un dibujo con propio rostro.

El 4 de marzo estaba en Progreso donde se encontró con su padre, tres de sus hermanas y dos sobrinos, quienes hicieron escala en su viaje de retorno a Cuba. En los días siguientes navegó hacia la isla de Jolbós, el islote de Contoy e Isla Mujeres, lugar en que departió con Augustus Le Plongeon, el arqueólogo británico-estadounidense que merodeaba por las antiguas ciudades mayas y que había descubierto el Chacmool. ${ }^{2}$ Finalmente, arribó a mediados o finales de marzo a Livingston, pueblo de pescadores, cuya población negra le impresionó favorablemente.

Solo disponemos de fechas exactas cuando se hallaba ya en tierra firme. El 25 de marzo andaba por Izabal y probablemente, el 2 de abril entraba en la capital de Guatemala.

Está claro que aquel recorrido tuvo mucho de aventura juvenil, como el mismo Martí lo señala en los fragmentos que han llegado a nosotros de su diario de ese periplo, documento de valor tes-

2 Véanse sus apuntes de viaje titulados "Jolbós", "Isla de Mujeres" y "Livingstone", OCEC, 5, pp. 39-50. timonial y que literariamente, podría considerarse como la muestra de un viaje de iniciación, tan usado en la narrativa del siglo XIX.

Es altamente probable que el diario fuera comenzado por el joven viajero desde el mes de marzo de 1877, en la región yucateca, y quizás lo había comenzado ya a escribir durante la travesía de La Habana a la ciudad mexicana de Progreso. Los apuntes de su paso por Holbox e Isla Mujeres hacen pensar que es posible que toda la ruta por la costa yucateca fue estampada en papeles perdidos en parte, posteriormente.

Dos elementos impactaron con fuerza al joven intelectual, que a pesar de haberse formado académicamente en las universidades españolas no cejó en su empeño, ya desde la adolescencia de atrapar la identidad continental, tan diferente, a su juicio, de la europea y de la estadounidense, punto de vista reiterado una y otra vez en sus escritos mexicanos. Por un lado, sus comprobadas visitas a Chichén Itzá y a otras ciudades mayas - las que describiría con admiración, ya en su madurez, en La Edad de Oro, en su revista para niñosle brindaron prácticamente una lección inolvidable de la grandeza material y espiritual de aquel pueblo, a la vez que dieron mayor firmeza a su condena de la dominación colonial. Tal importante contacto físico con esa antigua cultura americana estuvo acompañado, por otra 
parte, del intercambio con los pueblos mayas contemporáneos, herederos de aquella cultura originaria, pero sometidos al relegamiento y a la extirpación forzosa de muchos elementos de su cultura, tras la conquista a sangre y fuego, y durante los siglos de explotación y discriminación por el Imperio español y los decenios de la república criolla.

Tal relación directa con la gente y la cultura maya de Guatemala se puede apreciar, sobre todo, en su "[Diario de Izabal a Zacapa]", en el que se evidencia el choque difícil y aleccionador del joven universitario, periodista y poeta, o sea, del letrado, con ese sector popular, el más deprimido y alienado de aquella sociedad.

Las pocas páginas que se conservan de este documento, organizado en forma de capítulos por su autor -lo cual evidencia su voluntad de que llegara a un público amplio, más allá de sus dos destinatarios inmediatos-, demuestran la transformación no solo del criterio martiano, según fue conociendo a la pareja de arrieros que le condujo por las montañas, sino también de su perspectiva de análisis: el intelectual modelado por la llamada cultura occidental letrada comprende cuánto habría de aprender e incorporar de aquellos exponentes de una cultura popular, lo mismo para su pensamiento que para los diversos planos de su actuación personal. Y, aún más, entiende la necesidad de adecuar sus fundamentos éticos, su voluntad de originalidad y su afán renovador, para la que ya empezaba a nominar Nuestra América, a los patrones de una cultura originaria portada por una mayoritaria cantidad de la población viva y actuante de la Guatemala de entonces.

Desde luego, aquel fue un choque, cuyos efectos favorables hacia lo apuntado arriba se dejan advertir en el propio diario, aunque el cambio pleno de su perspectiva se irá perfilando en sus escritos guatemaltecos posteriores, como parte de un complicado y no lineal proceso que le tomaría buena parte de su madurez.

En esas páginas redactadas sobre la marcha, Martí halla poco humanos tanto espiritual como, a ratos, hasta físicamente- a Aniceto y a Lola, quienes le conducían a lomo de mula hacia Zacapa. El hombre "es un intérprete cansado, que dispone de muy buena voluntad, de una imbécil catadura, y de un escasísimo número de palabras que repite y aplica de modos diferentes." (OCED, 5, p. 55). A la mujer la estudia y la describe profusamente, con probabilidad porque se le hace más difícil la comunicación con ella. El marido es quien intercambia con mayor frecuencia con el joven viajero; pero ella se le hace impenetrable: "El pensamiento de esta mujer es una piedra azteca; no se puede leer en ella sin la ayuda de su marido" (OCEC, 5, p. 55). 
Ante semejantes juicios no hay dudas de que Martí se siente bien distante de la pareja maya, aunque se revela su inquietud lingüística al observar cómo Aniceto -obviamente persona de escaso repertorio en español- repite las palabras con variaciones en su aplicación, una manera de ampliar el vocabulario. Es evidente su rechazo físico de Lola, la mujer, cuyo rostro, para él, se contradice con su cuerpo, y cuya vestimenta, de clásica elegancia a su juicio, no se aviene con su persona.

Su perfil es correcto, menuda la nariz, breve la boca, bien hecha la frente, aguda la barba, acaba la figura un tocado casi griego, puesto que con las trenzas del cabello se ciñe el casco a manera de corona;mas todas esas perfecciones de la forma, abrutadas por la incultura, se convierten en fealdades numerosas por la falta de transparencia espiritual. Ni un rayo del alma se abre paso por entre esa tez de bronce. (OCEC, 5: p. 54).

Las "perfecciones de formas", obviamente, eran para el joven intelectual cubano las impuestas por la tradición grecolatina, mientras que la mujer maya las abruta. Obsérvese cómo este verbo le resta a Lola, al menos, parte de su condición humana, pues ella no es capaz de expresar transparencia espiritual, ni tampoco su alma. Y continúa el diario disminuyéndole aun más la naturaleza humana a Lola: "Es inaccesible a la bondad, a la pregunta, al silencio, al aseo, al cansancio, a la ternura." Y su propia conducta - continúa el diario- se ve alejada de lo humano: "Anda como quien va clavando estacas; horada donde pisa; lastima donde mira" (OCEC, 5: p. 54).

$\mathrm{Al}$ evidente rechazo físico se une entonces el espiritual: el 26 de marzo de 1877, al partir de Izabal, Martí ni siquiera sabe bien cómo comunicarse con ellos. Mas los días pasan, y de cierto modo hasta él se va sorprendiendo al hallar en sus guías el carácter humano, siempre, para Martí, refinado por los sentimientos. Y, además, en ese texto podemos entender cómo su autor llega hasta a disfrutar aspectos de ese mundo cultural portado por sus acompañantes y por muchas de las personas que encuentra a su paso.

Así va descubriendo, día a día y minuto a minuto durante la travesía, los hábitos y las costumbres de todo tipo - tan diferentes a las suyas- entre aquellos mayas, que van desde la manera de moverse por aquellas serranías, hasta la alimentación, la religiosidad y las formas del habla del español. ${ }^{3}$

3 "Quede atrás el matrimonio que platica, para convencerme de que cada clase humana tiene su lenguaje. Aniceto enamora a [palabra ininteligible encima de tachado "Lola"];-y yo ¿cómo lo pienso?-lo pienso filosóficamente,--no haría vibrar jamás una cuerda en el corazón dudoso de Lola. Yo no taño guitarra, ni mezclo el vos y el tú;-ni digo acotate por acuéstate, ni me zampo leguas como ciruelas, ni sé tejer la pita, ni embarrar un rancho, 
Sabemos que Martí desde antes, y hasta el último momento de su vida, sería mucho más que un mero observador de las culturas populares: fue todo un estudioso de ellas y siempre puso de manifiesto su voluntad de asimilarlas e incorporarlas a su propia experiencia, expresión y cultura.

Para apreciar la cultura maya Martí tenía, sin embargo, que romper con algunos prejuicios en torno a los pueblos originarios, fuertemente implantados en la cultura que pudiera calificarse de oficial y hegemónica, los cuales se infiltraban en su perspectiva, a pesar de su temprana simpatía por las culturas populares. En su etapa mexicana, entre 1875 y 1877, en más de una ocasión el cubano vio con desagrado lo que entendió como la sumisión o el servilismo de la población indígena. No pudo comprender entonces que si ello era una muestra de una conciencia colonizada, subordinada, era al mismo tiempo una elemental estrategia de supervivencia -quizás hasta inconsciente para muchos-, pero que significó no solo la preservación de vidas y de comunidades, sino también de elementos culturales que, en muchos casos, hasta fueron infiltrándose en la cultura criolla.

Es evidente que por entonces Martí no entendía el por qué de esa frecuente

ni limpiar un cañal, ni siquiera tomar aguardiente!- "Renuncio a Lola." OCEC, 5, 74. postura entre los pueblos originarios, al punto de que en México había llegado a considerar que esa conducta era impropia de seres humanos. ${ }^{4}$

Mas el contacto con los mayas favoreció el proceso de elaboración de su concepto de las culturas aborígenes de América, como civilizaciones cortadas por la conquista, la que encerró en sí mismos a sus portadores, y que la nueva nuestra América a que él aspiraba, trabajando unida ante sus rezagos coloniales y los nuevos peligros de sojuzgamiento por parte de la modernidad capitalista, no podría cumplir su cometido liberador mientras excluyese a esos pueblos. ${ }^{5}$

Fue justamente en Guatemala donde Martí enunció con claridad meridiana su concepto de nuestra América como un pueblo nuevo, mestizo (ya no estrictamente indio ni español), resultado de un

4 "Corren como los brutos; no saben andar como los hombres: hacen la obra del animal: el hombre no despierta en ellos." No obstante, en el mismo escrito, algunas líneas más adelante muestra comprensión de los factores que han provocado ese estado: "La raza está esperando y nadie salva a la raza. La esclavitud la degradó, y los libres los ven esclavos todavía: esclavos de sí mismos, con la libertad en la atmósfera y en ellos; esclavos tradicionales, como si una sentencia rudísima pesara sobre ellos perpetuamente". Boletín. Función de los Meseros." Revista Universal, México, 10 de julio de 1875. OCEC, 2: p. 117.

5 Véase Nuestra América, publicado en 1891, su brillante, previsor y maduro ensayo, en que pasa balance acerca de la dependencia continental debida a factores internos y externos y la necesidad de la unidad de nuestros pueblos para impedir el nuevo dominio del naciente imperialismo de Estados Unidos. 
proceso contradictorio, pero cuyo verdadero esplendor solo sería posible con la recuperación de su alma original. ${ }^{6}$ Fue también en allí donde Martí modificó, a plena conciencia, la historia de Centroamérica para introducir su llamado a la América nueva, unida y necesariamente inclusiva de las culturas indígenas.

En su pieza teatral Patria y Libertad (Drama indio), escrita a solicitud del gobierno liberal guatemalteco y llevado a escena con motivo de la independencia, el autor asumió la perspectiva indígena al enjuiciar el período colonial: entre los héroes contra la dominación hispana menciona a numerosos jefes indígenas rebeldes frente a la conquista y al colonialismo español: desde la quisqueyana Anacona hasta el inca Atahualpa y Túpac Amaru.

Como indica el mismo subtítulo de la obra teatral, la independencia, es decir, la búsqueda de Patria y Libertad se convierten por Martí en un Drama indio. Por eso no es sorprendente que el cabe-

6 Veamos sus palabras textuales en su trabajo "Los Códigos nuevos”, publicado en El Progreso, Guatemala, el 22 de abril de 1877: "Interrumpida por la conquista la obra natural y majestuosa de la civilización americana, se creó con el advenimiento de los europeos un pueblo extraño, no español, porque la savia nueva rechaza el cuerpo viejo; no indigena, porque se ha sufrido la injerencia de una civilización devastadora, dos palabras que, siendo un antagonismo, constituyen un proceso; se creó un pueblo mestizo en la forma, que con la reconquista de su libertad, desenvuelve y restaura su alma propia." OCEC, 5: p.89. cilla del motín liberador sea un mestizo llamado Martino, con lo cual el autor se nos presenta como portador al mismo tiempo de la cultura indígena y de la española -o más bien de la criolla-, es decir, de la cultura del pueblo nuevo de nuestra América. La obra, pues, sin duda alguna, evidencia una toma de partido martiana por el mundo indígena, sobre el cual Martí hace recaer el sufrimiento por las más atroces crueldades de la conquista y la colonia.

En una carta al español Valero Pujol, director de El Progreso, fechada el 27 de noviembre de 1877, Martí declara su propósito de dedicar la conmemoración de la independencia a los originarios pueblos mayas, al ser invitado a la tribuna el 16 de septiembre, por el también cubano José María Izaguirre, director de la Escuela Normal guatemalteca.

Volví los ojos hacia los pobres indios, tan aptos para todo y tan destituidos de todo, herederos de artistas y maestros, de los trabajadores de estatuas, de los creadores de tablas astronómicas, de la gran Xelahub, de la valerosa Utatlán. La manera de celebrar la independencia no es, a mi juicio, engañarse sobre su significación, sino completarla. Enumeré las fuerzas de Guatemala y las excité al movimiento y al trabajo.(OCEC, 5: p. 190) 
Es notable que el joven cubano en la enumeración de las fuerzas del país no deje de incluir a la población maya. Estas palabras creo que demuestran sin dudas cuánto había cambiado su perspectiva en su complejo y contradictorio proceso de acercamiento a los sectores populares de nuestra América.

El año siguiente, el 25 de febrero de 1878, El Porvenir acogía en sus páginas el texto martiano titulado Poesía dramática americana. Siguiendo su propuesta señalada antes en México, el cubano plantea la necesidad de presentar temas de nuestra América, de su historia, en la escena de la región. Así se pronuncia en favor de llevar al teatro a los héroes mitológicos e históricos mayas.

Y aquí, en el reino de Utatlán, donde Socoleo luchó, donde Uspantán asombró, donde los audaces Mames pusieron espanto tantas veces en las osadas filas de Castilla, jcuán fácil fuera al ánimo patriótico volver al mundo de la vida los ignorados bravos que bajo el casco del corcel o el látigo implacable del rubio Gonzalo, murieron tristemente! ¿Qué hacen en sus tumbas Ricab el animoso, Acxopil el prudente, Jiutemal el tenaz, Acxicuat avariento? ¿Dónde son idas la voz de los Ahaos, la respetada voz de los Calpules, aquellos cánticos de Xelahub, aquellas arengas de Tecún-Umán? Chignavitcolut no tiene poeta! Ni Sinacam, ni Sequechul tienen historiadores (OCEC, 5: p. 227).

En ese mismo texto se le escapa su vocación de escritor para el teatro y entrega una larga parrafada en que la princesa Ixcunsocil increpa "al dormido escritor americano" por no tomar como motivos los mitos, las leyendas, las historias y las epopeyas de nuestros pueblos. No es casual que el cubano dé voz a esa mujer maya: ella fue una princesa quiché raptada por el rey de los zutujiles, Zutujileb-Pop, hecho que dio lugar a una prolongada guerra, comenzada por su padre, Balam Acab, y continuada por sus sucesores Mancotah y Kicab, el Grande, hasta la victoria. Es obvio el paralelismo con la guerra de Troya y la intención martiana de incitar a no quedarse con la Ilíada griega, sino acudir a esta desconocida epopeya americana.

Aún no hemos podido precisar las fuentes de que se valió Martí para conocer de estas personalidades, hechos y leyendas de la antigua historia maya.

7 Tal precisión exige un cuidadoso y largo estudio del estado de conocimiento del tema maya, durante la segunda mitad del siglo XIX, y no es de dudar que, dado el marcado interés martiano por este, se hubiera mantenido al tanto de todo lo que estuvo a su alcance. En Las ruinas indias Martí relaciona algunas obras que probablemente le sirvieron como fuentes: Historia chichimeca, de Fernando de Alba Ixtlilxochitl; Recordación florida, discurso historial y demostración natural, material, militar y política del reino de Guatemala, de Francisco Antonio 
Mas no se puede pasar por alto que, más allá de recuperar tradiciones con un indudable fin artístico, se ha de observar cómo el Maestro declara explícitamente la importancia patriótica de su propuesta. Tal idea está en la misma línea de lo que había publicado un año atrás en Los códigos nuevos, como vimos antes, acerca de la incorporación de las culturas prehispánicas para la nueva América que él se planteaba.

Esa recuperación de las antiguas civilizaciones americanas era también escalón imprescindible para la salida de esa especie de postración en que, a su juicio, se hallaban sus descendientes. Su libro Guatemala, impreso en México a principios de 1878 , justamente cierra sus párrafos finales con una reflexión sobre este punto en que vuelve a hacer gala de su conocimiento de los antiguos pueblos mayas.

En una especie de llamado esperanzado hacia el futuro de Guatemala, Martí señala: "El porvenir está en que todos lo deseen” (OCEC, 5: p. 286). Y aunque afirma que todos "están preparados para ayudar", no deja de advertir un obstáculo: "Los indios a las veces se

Fuentes y Guzmán; Compendio de la historia de la ciudad de Guatemala, de Domingo Juarros; Historia de la conquista de la Nueva España, de Bernal Díaz del Castillo; Los viajes de Thomas Gage en la Nueva España y textos de Bartolomé de las Casas que no especifica. Veremos más adelante su uso como fuentes de José Milla y de Brasseur de Bourbourg. resisten, pero se educará a los indios”. Quizás preocupado por el sentido compulsivo de sus palabras, la suaviza a continuación de este modo: "Yo los amo, y por hacerlo haré” (OCEC, 5: p. 286).

Y para aclarar su verdadero pensar, señala en el párrafo siguiente la causas sociales e históricas justificativas del rechazo indígena a trabajar para ese futuro guatemalteco, y su absoluta seguridad de que será esa población india palanca decisiva de los cambios.
¡Ah! Ellos son -terrible castigo que deberían sufrir los que lo provocaron!-ellos son hoy la ré- mora, mañana la gran masa que impelerá a la juvenil nación. Se pide alma de hombres a aque- llos a quienes desde el nacer se va arrancando el alma. Se quiere que sean ciudadanos los que para bestias de carga son únicamente preparados (p. 286).

En su opinión, hay que abrirles libertad e inteligencia, para él, "la natural atmósfera del hombre.” (p. 286). Para sustentar esa confianza suya en la futura capacidad transformadora y aportadora de los pueblos mayas de Guatemala, pasa de inmediato a recordar así el desarrollo civilizatorio logrado en sus ciudades antiguas. 
Y ellos, los que vieron un guerrero español y lo copiaron en muy dura piedra en el circo asombroso de Cobán; los que tenían escuelas donde se loaba al alto Dios; los que elevaron torres, donde estudiaban los hermosos astros; los bravos paladines; los ingeniosísimos geómetras; los delicados tejedores; las heroicas mujeres; su senado de ilustres, más grave y respetado que nuestras severas Cortes de Justicia; los de grandes ejércitos, populosísimas ciudades, brillantes guerras; los defensores de Utatlán; los rebeldes Mames; los clásicos quichés, los profundos cantores del grande Whenb-Kaquix, llorado con lágrimas entre árabes y homéricos; los allá idos de México y Cuba; los vivaces niños, los celosos amantes ... (OCEC, 5: pp. 286-287)

Esos expositores de aquella cultura brillante y avanzadísima en su tiempo, han sido sustituidos, sigue Martí, por

...los que con el copetón sobre la frente, con el calloso pie agrietado, con la mirada imbécil, con la rodilla y el beso siempre prontos, con el esclavo espíritu, con la cargada espalda, a paso de mula o de buey, sirven hoy al cura, adoran nuevos ídolos, visten míseras ropas, y ni aleteo de águilas, sino sustento de arrobas, pasan montes y ríos, praderas y ciudades, hondos y cerros (5: p. 287).

En resumen, con llamativa lucidez para esa época, en opinión del cubano esos mayas de su tiempo eran trabajadores esforzados de vida espiritual apagada, por una historia de conquista y de dominación, y, aún más, como escribe Martí luego: "Son resignados, inteligentes, naturalmente artistas, sin ningún esfuerzo buenos" (p. 287). Ante ese manojo de virtudes, termina su análisis reiterando su confianza en el indio preparado, no sometido al oscurantismo y la explotación inicua. "¡Qué gran pueblo no puede hacerse de ellos, haciendo, por ejemplo, a manera de una escuela normal de indios! ¡Un nuevo apostolado es menester!" (p. 287)

Es notable esa significación otorgada por Martí a esos pueblos mayas coevos en una obra como Guatemala, cuyo objetivo principal era propagandizar los éxitos de la reforma liberal y atraer la aprobación y el interés de los lectores por aquella, lo que explica su tono amable hacia ese proceso, aunque nunca adulador de su líder, el presidente Justo Rufino Barrios. Empero, Martí también quiere entregar los encantos del país, de su naturaleza de su gente, de su riqueza espiritual y artística. Así, al cantar a la pequeña nación centroamericana, el autor, de hecho, estaba poniendo un ejemplo de cuánto podía y debía hacer nuestra América en su conjunto. 
Por tanto, sus análisis y enjuiciamientos sobre los mayas resultan valederos para todos los pueblos originarios de nuestra región, por más que sus lecturas sobre esa antigua cultura y su visita a sus ruinas arquitectónicas y urbanísticas le hayan provocado esa enorme admiración que le hizo volver sobre ella en momentos posteriores de su vida.

A varios estudiosos de la obra martiana no ha dejado de llamarnos la atención la ausencia de referencia en Guatemala y en otros de sus textos sobre el país, a las leyes dictadas por el gobierno liberal de Barrios por aquellos años, que revivían de hecho los trabajos forzados de las comunidades indígenas en las labores agrícolas y especialmente en las grandes plantaciones de café. Es raro que un enemigo de la esclavitud, como lo fue Martí casi que desde su niñez, no se pronuncie de algún modo al respecto. Al parecer, los esquemas liberales en materia económica -que por esos años eran aún fuertes en sus ideas acerca del desarrollo económico- le impidieron comprender plenamente cuánto lesionaban esas leyes la libertad personal y colectiva, así como los ancestrales derechos de propiedad de las comunidades indigenas. No obstante, ello no desvaloriza el entusiasmo martiano por la antigua cultura maya ni su excepcional criterio en su momento acerca del papel que le asignaba a sus sucesores.
El viaje de arribo a Guatemala y la estancia en la hermana nación fueron también aprovechados por el joven cubano para identificarse con el entorno de las tierras mayas de Yucatán, Belice y la propia Guatemala, y para así continuar asentando su criterio acerca de la unidad necesaria entre hombre, sociedad y naturaleza, pieza angular de su filosofía, en mi criterio, reforzada justamente desde que descubriera la imponente naturaleza continental a su llegada a México en 1875.
Allá, en el día primero, allá análo- go a mí, hallábame bien respiran- do el mar y caballero en la altura; escalando el pico y serpeando la pendiente; salvando el paso estre- cho y ladeando la áspera quebra- da; olvidado con la vecindad de las nubes de mansedumbre de la bestia; gustando del inefable y utilísimo placer de los peligros, y ¡extraña cosa! jamás recibo yo de la grandeza aire ni impresión que no sean míos; de mi mismo pecho brota la potencia con que admiro; y el aire nuevo que me lo agran- da y me lo inflama, de mí nace, y valgo lo que son, y jamás llega la hermosura del espectáculo a la altivez con que lo siento (OCEC, 5: pp. $61-62)^{8}$

8 En sus apuntes para sus clases de Filosofía en la Escuela Normal de Guatemala, encontramos esta significativa definición suya de naturaleza: "Naturaleza es todo lo que existe, en toda forma,--espíritus 
La cultura maya no fue, pues, mera curiosidad o exótico atractivo para Martí, ni sus sistemáticas reseñas a ella pueden estimarse gentil referencia de ocasión para el público guatemalteco que lo escuchó o lo leyó mientras residió en el país. Su público era la gente letrada, que en su aplastante mayoría no compartía semejantes perspectivas acerca de los pueblos originarios, aunque el joven cubano supiera ganarse la simpatía de muchos. ${ }^{9}$ Por el contrario, esa cultura autóctona de nuestra América ocupó aposento destacado en el cuerpo de la singularmente rica, diversa y variada cultura martiana como una de las numerosas fuentes de que se nutrió, y por eso, recurrirá explícitamente a ella en más de una ocasión años después de abandonar Guatemala.

El 6 de julio de 1885 Martí preparó una de sus "Cartas" para el diario La Nación de Buenos Aires, dedicada a varios temas del verano estadounidense.Uno de ellos fue acerca de los cheroquíes de Norteamérica,

y cuerpos; corrientes esclavas en su cauce; raíces esclavas en la tierra; pies, esclavos como las raíces; almas, menos esclavas que los pies. El misteriosos mundo íntimo, el maravilloso mundo externo, cuanto es, deforme o formado, luminosos u oscuro, cercano o lejano, vasto o raquítico, licuoso o terroso, regular todo, medido todo menos el cielo y el alma de los hombres- la virtud es Naturaleza." (OCEC, 5: pp. 209-210).

9 Así lo evidencia la nota al pie que su amigo, el director de El Progreso, incluyera en el artículo martiano "Los Códigos nuevos" objetándole el uso del término civilización para referirse a los culturas nativas encontradas por los conquistadores. quienes habían creado una escuela para sus hijos, y al describirla la compara así con la de las ciudades mayas: "La escuela tiene dos habitaciones, como las de Utatlán, de los cachiques [sic] que a botes de lanza exterminó Alvarado: una habitación para los niñas, y para los niños otra: de las escuelas de Utatlán salían los niños indios en procesión, a aquel sol suave, con sus vestidos blancos: jsalían cantando!" (OC, 10: $\mathrm{p} .273)^{10}$

No solo de los héroes y de las antiguas ciudades mayas se ocupa Martí. A finales de 1888 Martí escribió otra de sus crónicas sobre Estados Unidos, titulada "Vida norteamericana", publicada en el diario La Nación de Buenos Aires el $1 .^{\circ}$ de febrero del año siguiente. Allí da la curiosa noticia de un hombre que andaba por las aguas del río Hudson, junto a Nueva York, y lo compara "con los indios de Guatemala, que cruzan a pie con un baúl a la cabeza, la corriente del río Tambor" (OC, 12: p. 103). Aunque no lo diga, tal parece que quiere mostrar mayor intrepidez entre los indígenas guatemaltecos, obligados a entrar en el río por necesidades de subsistencia, no por mero exhibicionismo quizás de corte mercantil.

10 José Martí. Obras completas, 27 tomos. La Habana, Editorial Nacional de Cuba, 1963-1965. Tomo 10, p. 273. En adelante se cita OC, la primera página corresponde al tomo y las siguientes a las páginas. 
En enero de 1888, apareció en el mensuario neoyorquino El Economista Americano un amplio comentario martiano acerca del libro Guatemala, la tierra del quetzal, de W. I. Brigham. A diferencia de otras obras de viajeros estadounidenses por tierras de nuestra América, Martí encuentra que este es un libro "honrado" aunque no deja de señalarle algunos errores de "juicio o equivocación histórica” (OC, 7: p. 180) e introduce varias observaciones en relación con la cultura maya.

Es relevante su amplio comentario acerca de la pelea de los mayas frente a los conquistadores que alcanza altura de trágica epopeya protagonizada por Tecum-Unam.

...y llegó a ser príncipe de Utatlán hermosa el bravo y magnífico Tecum-Unam, odiado de cakchiqueles y zutujiles, que cayó muerto, con más heridas que poros, a los pies de Alvarado, cuando la lanza del español rubio tundió de un golpe el pájaro real que en defensa de su príncipe cayó sobre el de España, ¡el quetzal del Quiché, enamorado de su belleza y albedrío, que muere cuando cae preso, o cuando se le quiebra la pluma verde de la cola! (OC, 7: p. 183) 11

11 Años después en su discurso ante los delegados a la Conferencia Internacional Americana, pronunciado en la Sociedad Literaria Hispanoamericana de N Nueva York, el 17 de diciembre de 1889,
Hermosa y simbólica imagen la empleada por Martí para indicarnos el sentido natural de la libertad entre aquellos mayas y su héroe. Ya para esa época, convertido en un sistemático defensor de la necesidad de la acción unida de nuestra América, Martí escribe unos brevísimos apuntes que titula "Poema Americano", en los cuales reúne los nombres de cuatro personalidades luchadoras por la libertad de la región: "Tecum Unam, Sucre, Túpac Amaru, Juárez" (OC, 18; p. 286). De ellas, tres fueron indios: el jefe maya enfrentado a la conquista; el andino, precursor combatiente contra el colonialismo; el mexicano, tenaz defensor de la república liberal.

Volviendo al texto sobre el libro de Brigham, el viajero por Guatemala, Martí también contrasta la destructora conquista española con la altura civilizatoria de la gente nativa "que hizo a Izmachi ${ }^{12}$ de piedra y cimiento, no era por cierto indiada ruda; pero que, a la lanza de Alvarado, el rubio ágil y bribón que quemó vivo al señorío indio y le robó su más galana mujer, cayó bajo la dominación de aquellos en cuya historia no quiere entrar Brigham..." (OC, 7: p. 281)

Martí repitió la idea de que las divisiones entre los pueblos originarios fueron factor decisivo para la conquista española. En la enumeración de tales conflictos incorpora así las habidas entre los mayas de Guatemala: "por entre quichés y zutujiles vence Alvarado en Guatemala”. (OC, 6: p. 136).

12 Se le consideraba entonces la capital de los antiguos quichés. 
En el mismo comentario sobre esa obra apunta que su autor estuvo en las ruinas de Quiriguá, "en cuyos monolitos perpetúa la imagen del hombre barbado, como doquiera que hubo mayas, la memoria de aquel sabio Votam que les fue de Cuba..." (p. 182).

Curiosa esta referencia martiana a su patria. En verdad no hay pruebas fehacientes de que ese mito adujera el origen insular de Votam, a veces llamado también Balum-Votam. ${ }^{13}$ Este fue el héroe llegado por mar de la leyenda de los mayas de Chiapas, cuyos rasgos descritos por el sacerdote español Ramón Ordoñez y Aguíar ${ }^{14}$ concuerdan con los de Quetzalcoatl. Según esa leyenda Votam fue el fundador de un reino de donde salieron varios grupos mayas como los tzentales y los quichés entre otros.

Años antes, en 1883, en una de sus "Escenas norteamericanas" presenta a Elisha Hunt Allen, embajador del reino de Hawai en Estados Unidos, y lo compara con Balum-Votam, "de barba blanca, que venía del Este y daba leyes, y amor,-que es mejor ley,- y tiernos consejos, al pueblo nerviosos, guerreador y vivo de los viejos mayas" (OC, 9: p. 336$)^{15}$

13 En ocasiones Martí escribe Votán.

14 Recogió algunas historias sobre este personaje entre los indios choles que vivían cerca de Palenque y las dio a conocer hacia finales del siglo XVIII.

15 "Cartas de Martí. Galas de Año Nuevo." La Nación, Buenos Aires, 18 de marzo de 1883. Por cierto, años después Martí mudó su opinión acerca
En rigor, tal comparación resultaba fallida, pues Allen no tenía nada que ver con el generoso sabio de los mitos mesoamericanos, sino que fue un desembozado anexionista que trabajó justamente hasta lograr que Hawai perdiera su independencia y se convirtiera en un dominio estadounidense.

El sabio ilustrado reaparece también en los breves apuntes martianos para su drama acerca de Chacmool. Allí escribe que Votam compone rayos y da luz, y está contento, pues el indio despierta (OC, 21: p. 360). También en un fragmento habla de alguien cuyo nombre no da, que sabe de Yucatán como si "hubiera andado con Le Plongeon por aquellas malezas donde veneran aún al hombre combado, que es pie de Cuba, a Balum-Votán, que les llevó la paz y la ciencia”. ${ }^{16}$

Quizás una de las mejores muestras del manejo martiano de los conocimientos acumulados hacia el último cuarto del siglo XIX, acerca de los antiguos mayas sea su curiosa referencia al Popol Vuh, en un texto de mayo de 1884, del mensuario La América, entonces bajo su dirección. Aunque no está firmado, el estilo denota indudablemente su autoría. Se titula "El Popol Vuh de los quichés. Páginas del libro de José Milla" (OC, 5: pp. 209-208).

de la presencia estadounidense en aquel reino del Pacifico.

16 OC, 22, 23, fragmento 31. 
El grueso del escrito son citas acerca de la creación tomadas de la Historia de la América Central, desde su descubrimiento hasta su independencia, obra salida de las prensas solo cinco años atrás. Martí se limita a un breve comentario inicial y a otro que da hilación a las citas textuales. El texto con el que abre señala que esos asuntos solo son desconocidos por quienes no los conocen, con lo que apunta a la fuerte impresión causada entre quienes ya habían tenido acceso al manuscrito maya de Chichicastenango, publicado en París en 1864 por Charles-Étienne Brasseur de Bourbourg, uno de los pioneros en los estudios de los mayas antiguos. La labor de José Milla y Vidaurre, a quien Martí había conocido durante su residencia guatemalteca, es presentada favorablemente por este, pues dice que el historiador entregó una "imparcial y sencilla relación de la cosmogonía indígena", leída por ese autor con "inteligencia y reproducida con sinceridad" (OC, 19: p. 105).

Luego de las frases del Popol Vuh referidas al creador, Martí copia la formación de la vida narrada por Milla, siguiendo la leyenda maya y dice que esa cosmogonía "no carece de grandeza" (p. 105) y que la creación del universo según los quichés "no carece de poesía." (OC, 19: p. 206).

Este escrito de La América va acompañado, caso excepcional en la publicación, de notas aclaratorias, redactadas seguramente por el propio Martí, en las cuales se revela la amplitud de su información acerca de los pueblos indígenas de Mesoamérica. Así, en una de ellas brinda el dato tomado de los comentarios de Brasseur de Bourbourg al llamado Libro sagrado quiché acerca de la semejanza entre Gucumatz, Quetzalcoátl y Cuculcán y del símbolo de la serpiente con plumas de quetzal (p. 206).

Ese afán martiano por hacer partícipe a sus lectores del pensamiento y de la literatura maya, como efectuó con otras muestras escritas de los pueblos antiguos del continente, pone de manifiesto la actualización informativa del Maestro, su deseo de que tales conocimientos formaran parte del acervo cultural de nuestra América y el por qué de su admiración de aquellas culturas a las que llamó majestuosas, por no desmerecer en su opinión, ante las culturas de la Antigüedad greco-latina (OC, 6: p. 18$)^{17}$.

Finalmente, la cultura maya fue también incluida por Martí en su revista para niños La Edad de Oro. En el número 2 de la publicación, correspondiente a agosto de 1889, apareció su artículo "Las ruinas indias", todo un fervoroso canto a la grandeza de las antiguas culturas americanas. Aunque el texto se centra en las culturas

17 Recuérdese que en plena madurez escribió en su ensayo cenital titulado Nuestra América (1891): "La historia de América, de los Incas, acá, ha de enseñarse al dedillo, aunque no se enseñe la de los arcontes de Grecia. Nuestra Grecia es preferible a la Grecia que no es nuestra”. (OC, 6: p. 18) 
del centro de México y de Yucatán, en el párrafo inicial entrega consideraciones que extiende a los nahuatles [sic], mayas, chibchas, cumanagotos, quechuas, aimaraes [sic], charrúas y araucanos, en largo recorrido de norte a sur por los pueblos originarios del continente, con diversos grados de desarrollo entre ellos. Y dice de todos en conjunto: "Fue una raza artística, inteligente y limpia" (OC, 18: p. 380).

No pueden pasarse por alto estas tres cualidades atribuidas por Martí a los pueblos originarios de nuestra América, pues ellas rechazan, por contraste, la entonces muy difundida imagen de su barbarie, justificativa de su dominación y discriminación.

En el segundo párrafo del citado artículo nos pasea por las principales ciudades mayas, de las que va entregando alguna de sus características, y entre ellas menciona así a Utatlán, la de Guatemala: "aquellos maestros amorosos y niños mansos de Utatlán”. Obsérvese que los adjetivos insisten en cualidades de valor humano, y, sobre todo, en que repite la existencia entre ellos de un sistema educacional, algo impropio de pueblos primitivos, atrasados, bárbaros.

Por último, dedica un fragmento al quetzal, en el cual insiste en presentar al ave como símbolo de la libertad: "El quetzal es el pájaro hermoso de Guatemala, el pájaro de verde brillante con la larga pluma, que se muere de dolor cuando cae cautivo, o cuando se le rompe o lastima la pluma de la cola. Es un pájaro que brilla a la luz, como las cabezas de los colibríes, que parecen piedras graciosas, o joyas de tornasol, que de un lado fueran topacios, y de otro ópalo, y de otro amatista" (OC, 18: p. 381)

¿Acaso, se pregunta el lector, el pájaro no es una manera martiana de brindarnos el amor a la libertad de los pueblos mayas? Ojalá siempre el quetzal del Quiché esté a nuestro lado y nos enseñe el camino de la resistencia y la libertad. 